\title{
Tongue Tie in Infancy
}

Sophie Shay, $M D^{1}$

Rachel Mandelbaum, $B A^{2}$

Nina Shapiro, MD FACS ${ }^{1, *}$

\author{
Address \\ ${ }^{*}, 1$ Department of Head and Neck Surgery, David Geffen School of Medicine at \\ UCLA, Los Angeles, CA, USA \\ Email:nshapiro@ucla.edu \\ ${ }^{2}$ David Geffen School of Medicine at UCLA, Los Angeles, CA, USA
}

Published online: 2 July 2016

(C) Springer International Publishing AG 2016

This article is part of the Topical Collection on Otolaryngology

Keywords Ankyloglossia · Frenotomy · Lingual frenulum • Surgical intervention

\section{Opinion statement}

Ankyloglossia, or "tongue tie," classically involves a short or thickened lingual frenulum that may prohibit tongue protrusion. However, the diagnosis, evaluation, clinical significance, and management of ankyloglossia are widely variable and controversial. Despite attempts to create standardized diagnostic criteria for ankyloglossia, there has yet to be a universally accepted system. Management of ankyloglossia often includes a multidisciplinary approach including lactation consultants, speech language pathologists, pediatricians, and otolaryngologists. Observation or conservative management for asymptomatic infants or infants with minimal or well-compensated symptoms is a reasonable option, whereas surgical intervention may be warranted for infants and children with ankyloglossia that has significant impact on breastfeeding or speech. Frenotomy (also known as frenulotomy) is a relatively simple procedure that can be performed at the bedside or office setting in very young infants, precluding the need for general anesthesia. Frenuloplasty is usually performed on older children and should be performed in the operating room with general anesthesia. Overall, there is insufficient evidence to definitively associate ankyloglossia with breastfeeding or speech deficits. Surgical intervention for ankyloglossia should be recommended with caution and performed only on infants or children with clear findings of ankyloglossia on physical exam and a documented history of breastfeeding or speech difficulties; the timing and method of treatment should be tailored to the individual infant or child. Frenotomy or frenuloplasty should only be performed by providers with adequate training and experience in order to minimize complications.

\section{Introduction}

Ankyloglossia, commonly known as "tongue tie," etymologically originates from the Greek "agkilos" (curved) and "glossa" (tongue) and refers to congenital oral anomalies with varying degrees of restricted tongue 
mobility. Characteristically, ankyloglossia involves an abnormally short or thick lingual frenulum or a highly attached genioglossus muscle insertion that tethers the tip of the tongue and prevents tongue protrusion. Since the initiation of the World Health Organization's movement towards reliance on breastfeeding during an infant's first year of life, there has been significant interest in infants affected by ankyloglossia [1]. Nonetheless, the clinical significance, diagnosis, classification, and treatment of ankyloglossia all remain controversial [2-5]. Breastfeeding challenges as a result of ankyloglossia include difficulty with latching, maternal nipple pain, and insufficient feeding, which may put the infant as risk for early infant weaning or failure to thrive in more extreme cases [6]. Later in life, the restrictions on tongue mobility caused by ankyloglossia may include cuts from teeth on the frenulum, difficulties with licking lips, and more socially debilitating problems with speech articulation; however, definitive studies on these limitations are lacking [6-8].

Messner et al. (2000) demonstrated significant variation in opinion regarding the clinical significance of ankyloglossia and indications for treatment [9]. Sixtynine percent of surveyed lactation consultants believed that ankyloglossia was frequently associated with feeding problems, while the same was reported by only $6 \%$ of surveyed otolaryngologists and $1 \%$ of pediatricians. Regarding speech difficulties, $60 \%$ of otolaryngologists believed that ankyloglossia was at least sometimes associated with speech difficulties, compared to only $23 \%$ of pediatricians and $50 \%$ of speech language pathologists. Moreover, the need for surgical intervention was controversial, with surgery being recommended for feeding, speech, and social/mechanical reasons by 53, 74, and $69 \%$ of otolaryngologists, respectively, compared to only 21,29 , and $19 \%$ of pediatricians.

\section{Epidemiology}

The reported incidence of ankyloglossia among infants ranges from 0.1 to $10.7 \%$, with studies investigating oral mucosa abnormalities finding a lower prevalence of tongue tie (0.1-4.4\%) than studies looking at ankyloglossia alone (4.2-10.7\%) [6, 9-12]. A definitive incidence in the literature has been elusive, likely secondary to the absence of standardized diagnostic criteria. In regards to gender, there appears to be a slight male predilection for ankyloglossia over females, though some studies have also found equal gender ratios. Race and ethnicity have not been found to be predisposing factors [6].

\section{Etiology}

The etiology of ankyloglossia is generally unknown. The vast majority of infants with ankyloglossia are healthy infants without evidence of other congenital anomalies [12, 13]. Nonetheless, a few case series have found an association between ankyloglossia and rare congenital syndromes such as X-linked cleft palate syndrome [14], Kindler syndrome [15], van der Woude syndrome [16], and Opitz syndrome [17]. A genetic basis of ankyloglossia has also been suggested, as several studies investigating factors associated with ankyloglossia have found a positive family history among 10-53\% of patients [7, 8, 13]. Familial pedigree studies have also found evidence to support genetic transmission of ankyloglossia, though the inheritance pattern has yet to be clearly established $[12,13,18]$. Of particular focus in the literature is the T-box transcription factor gene TBX22, which has also been implicated in X-linked cleft palate [19]. The TBX22 gene in humans is located on the long arm of the $\mathrm{X}$ chromosome and expressed through eight coding exons related to the development of the posterior palatal shelves and the caudal tongue [20, 21]. Mutations of the TBX22 gene have been found in patients with cleft palate and ankyloglossia [19, 20, 22-24]. Maternal cocaine use during pregnancy has also been associated with ankyloglossia. A case-control series by Harris et al. (1992) found that partial ankyloglossia was 3.2 times higher among children exposed to cocaine in utero [25].

\section{Diagnosis}

The diagnosis of ankyloglossia is particularly challenging. Although several classification systems have been proposed, none offer correlation with functional impairments, and there is currently no universally accepted system [2-5]. Similarly, the functional limitations are difficult to assess as neither the maternal nipple nor the infant's tongue are visible during breastfeeding. Careful assessment by manual examination of the undersurface of the tongue and the attachments of the frenulum is necessary to reveal limitations in mobility. Anterior ankyloglossia is more readily apparent to the eye due to the prominence of a shortened frenulum and tethering of the tip of the tongue. Anterior ankyloglossia is characterized by insertion at the tip of the tongue (type 
I) or slightly behind the tip (type II). Posterior ankyloglossia is characterized by a thickened frenulum (Type III) or a submucosal frenulum presenting as a flat, broad mound absent of any typical protruding frenular tissue, and restricting base of the tongue mobility (type
IV) $[4,26,27]$. With more subtle physical findings and functional impairment, posterior ankyloglossia poses an even further diagnostic challenge, and due to a paucity of available literature, its incidence and relevance remains controversial [28, 29•, 30].

\section{Treatment options}

Frenotomy, or frenulotomy, is a quick procedure that is performed relatively easily to correct both anterior and posterior ankyloglossia. For young infants, the procedure is often performed at the bedside or in the office, often by otolaryngologists. Generally, the tongue is superiorly retracted to expose the lingual frenulum which is then sharply incised, usually with sterile iris scissors. Care should be taken during the procedure to avoid the sublingual and submandibular gland openings along the floor of mouth by cutting the frenulum close to the ventral surface of the tongue. The incision is not sutured. There is usually very little blood loss following the procedure; any minor amount of bleeding can be controlled with localized pressure. The infant is allowed to feed immediately following the procedure.

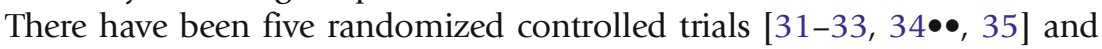

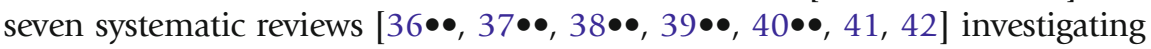
the effects of frenotomy on breastfeeding. However, experts acknowledge that these existing studies alone are largely insufficient to support a clear relationship between frenotomy and improvements in breastfeeding, with large variations in diagnosis of ankyloglossia and methods of frenotomy procedure, lowquality of evidence from case-control studies and case series, and a notable lack of data on nonsurgical interventions for ankyloglossia. Nonetheless, randomized controlled trials have found that frenotomy does improve breastfeeding immediately or within 5 days of the procedure when compared to sham surgery or observation $[32,33,34 \bullet \bullet]$. Among 55 patients randomized to frenotomy compared to 52 patients without intervention, Emond et al. (2014) found improvements in maternal self-efficacy measures of breastfeeding but found no improvement of frenotomy on the Latch, Audible swallowing, nipple Type,

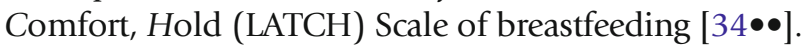

The impact of frenotomy on reduced maternal nipple pain during breastfeeding has been inconsistent. Buryk et al. (2011) found in a randomized controlled trial that measures of maternal nipple pain decreased significantly immediately following the procedure compared to infants treated with sham procedure, but these improvements in nipple pain were not demonstrated at 2week or 2-month follow-up [33]. Similarly, Dollberg et al. (2006) also found immediate relief in nipple pain following frenotomy [35]. However, Emond et al. (2014) and Berry et al. (2012) found no differences in maternal nipple pain scores following frenotomy $[32,34 \bullet \bullet]$.

A systematic review by Chinnadurai et al. (2015) concluded that there is insufficient evidence to assess the efficacy of frenotomy on nonbreastfeeding outcomes such as speech or social outcomes. Chinnadurai et al. (2015) found that frenotomy did tend to improve bottle feeding and tongue mobility in 
social situations such as eating ice cream, while there were limited cohort studies suggesting an improvement in speech articulation and intelligibility following frenotomy [43••]. A systematic review by Webb et al. (2013) also found insufficient evidence to support frenotomy for the treatment of speech articulation $[40 \bullet \bullet]$.

The timing of frenotomy in the available literature has been variable, with ages at the time of procedure ranging from 1 to 18 days for those experiencing

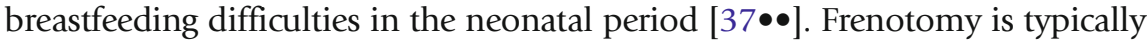
performed at the bedside or in the outpatient clinic setting. General anesthesia is usually not necessary for those under 3 months of age [44]. Utilization of frenotomy in an outpatient clinic setting without general anesthesia has been found to be safe and cost-effective, with high parent satisfaction scores [45-47]. In a survey study of patients and/or guardians by Klockars and Pitkaranta (2009), frenotomy with no or local anesthesia was found to be safe and costeffective [18]. Some case series report the use of local anesthesia or sucrose during the procedure $[37 \bullet \bullet, 47,48 \bullet]$; however, many do not mention this technique, and even advocate against the use of local anesthetic [10, 33, 35, 49]. Ovental et al. (2014) found that topical benzocaine was not beneficial in decreasing crying time, which was used as a measure of infant pain [50 $]$.

Frenotomy has been shown to be largely safe procedure with the majority experiencing no complications $[38 \bullet \bullet, 47]$. The most frequently reported complication is minor bleeding which is usually addressed with local pressure for hemostasis. Injury to the submandibular ducts, surgical site infection, and

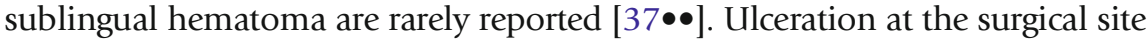
and delayed wound healing have also been reported [47]. Rates of reoperation range from 0.1 to $27 \%$ among available case series, though many of these case series include both infants and children, with higher rates of reoperation in

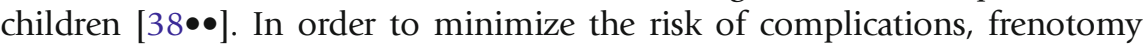
should only be performed by experienced and trained practitioners. However, in a survey of 425 North American physicians, $22 \%$ reported performing frenotomy, while only $10 \%$ were formally trained to perform the procedure [51]. Recurrence and necessity for procedural revision, secondary to inadequate release of the lingual frenulum or development of scar tissue, may occur more frequently in cases of posterior ankyloglossia than anterior cases, with revision rates of 21.1 versus $3.7 \%$ respectively reported by Hong et al. (2010) [28].

A handful of studies have investigated the utility and safety of $\mathrm{CO}_{2}$, argon, and Nd:YAG laser technique in frenotomy, though the use has been primarily demonstrated among older children and adults [52-55]. At this time, experience with laser frenotomy in infants is exceedingly limited. Those that advocate laser frenotomy report that the use of laser allows for improved surgical precision with minimal bleeding, decreased wound contraction and scarring, no need for suturing, and improved postoperative pain [56-58]. In these studies, laser frenotomy has been successfully performed as an outpatient and/or in the clinic setting. Although the use of laser appears to have some advantages, there are notable associated risks. Protective eyewear is necessary for the surgeon and surgical assistants, who all need to be properly trained in laser safety procedures. The patient's skin, teeth, oral tissues, and airway are at risk of accidental laser injury. Thus, while laser frenotomy does appear to be a reasonable alternative to conventional surgical methods, it has yet to become widely accepted among otolaryngologists. This may be attributable to the relative ease of performing 
conventional surgical frenotomy among infants without risk of the potential complications of laser use.

Frenuloplasty is a generally performed to treat ankyloglossia in older infants between 1 and 2 years of age, as well as older children and adults. For infants and young children undergoing frenuloplasty, treatment under general anesthesia would be required. General anesthesia can be achieved with either intravenous sedation and/or intermittent mask ventilation. Frenuloplasty is preferred for these children over frenotomy in order to decrease the risk of scarring and need for reoperation. Nonetheless, frenuloplasty may still result in scar contracture and persistent tongue tethering.

A traditional frenuloplasty is performed as a horizontal-to-vertical plasty. In this technique, the tongue is retracted superiorly to expose the lingual frenulum. The lingual frenulum is then sharply incised along the ventral surface of the tongue. As with frenotomy, care is taken to avoid injury to the submandibular ducts. For some patients, the genioglossus muscle may have to be incised for adequate release of the ankyloglossia. The defect along the ventral surface of the tongue is then closed primarily in a single layer using absorbable sutures.

An alternative method of frenuloplasty is a Z-plasty technique which serves to release the lingual frenulum and increase the length of the ventral tongue scar [49]. In a classic Z-plasty, opposing $60^{\circ}$ triangles are created and rotated to lengthen the scar. The lingual mucosa is then closed with absorbable sutures. Comparing frenotomy to Z-plasty frenuloplasty among infants and children ranging from 5 days to 8 years of age, Yousefi et al. (2015) found that frenuloplasty had significantly greater improvements in speech articulation, reduced maternal breast pain, increased lingual mobility, and parent satisfaction. Heller et al. (2005) advocated using a 4-flap Z-frenuloplasty and reported significant improvements in frenulum length, tongue protrusion, and speech articulation compared to traditional horizontal-to-vertical frenuloplasty among children 3-9 years of age [59]. Some have also proposed that in ankyloglossia, the foreshortened lingual frenulum coincides with contracture of the genioglossus muscle. Thus, Choi et al. (2011) advocate the combination of Zplasty with genioglossus myotomy [60]. After incising the ventral tongue mucosa, Choi et al. (2011) describe using electrocautery to horizontally incise and release the tightened genioglossus muscle. These investigators found no difficulties with tongue movement or articulation following genioglossus myotomy and reported improved speech outcomes.

\section{Supplementing with a breast pump}

Within current literature, there is a paucity of data available regarding nonsurgical methods of managing ankyloglossia. In a retrospective review of 287 pediatric surgery outpatients with ankyloglossia, Wright (1995) reported that 16 patients did not require intervention, 66 deferred the decision for management at the initial consultation and ultimately did not undergo surgery, and 101 were referred to speech pathology, of which 49 did not require subsequent operation, for a total of $46 \%$ of patients that did not require surgical intervention. Riskin et al. (2014) surveyed Israeli mothers with infants affected by ankyloglossia and reported that these mothers were more likely to use a breast 
pump to supplement ineffective breastfeeding [61•]. Infants with ankyloglossia can be fed expressed breast milk from a bottle until they are able to transition to breastfeeding, usually around 6-9 weeks of age.

\section{Finger feeding}

Finger feeding using feeder-controlled methods (Hazelbaker FingerFeeder or feeding tube in a bottle) can also be utilized [62]. The feeder's finger and the feeding tube are held inside the infant's mouth across the lips. This method works via operant conditioning to train the infant in appropriate feeding techniques. Feeding starts when the tongue tip protrudes over the alveolar ridge and the posterior tongue drops slightly. Feeding with the fingerfeeder stops when the tongue retracts or when the posterior tongue pushes against the feeder's finger.

\section{Nipple shield}

Nipple shields may also be used during breastfeeding, particularly wider nipple shields, though for infants with severe tongue retraction from ankyloglossia, the use of a nipple shield may exacerbate nipple pain by stimulating the infant's bite reflex.

A multidisciplinary approach may be beneficial in the management of ankyloglossia. Involvement of lactation consultants should be undertaken to help mothers find optimal latch positioning while breastfeeding. Riskin et al. (2014) found that a lactation consultant helped mothers of infants with ankyloglossia with breastfeeding problems [61•]. Infants with ankyloglossia are unable to bring their tongues down into the mouth to allow grasp of the nipple. A tight, diagonal grasp of the infant against the mother's body or a semi-reclined position of the mother may allow the infant to gape widely and form a deep latch to aid in expressing milk. Modifications to bring the infant's chin and tongue closer to the breast may also be helpful. Denting the breast at or just below the areolar margin with a finger forms a hollow for the infant's chin, which then allows for closer latch of the infant's lower lip and tongue onto the nipple [62].

Tongue exercises have been proposed for infants that do not undergo surgical intervention and for postoperative patients to prevent scarring. While oral exercises alone are unlikely to cure limitations of severe ankyloglossia, participation in tongue exercises specifically designed by a lactation consultant or occupational therapist may help to train the infant in tongue extension and protrusion as well as limit maladaptive compensatory tongue movements. Exercises primarily focus on tongue elevation and protrusion $[62,63]$. Caregivers are instructed to insert their finger underneath the infant's tongue and perform sweeping motions as well as direct pressure upwards and downwards to facilitate elongation of the frenulum [62]. Massage of the undersurface of the tongue has also been posited to help loosen tissue and promote increased tongue mobility. Another commonly used strategy is the gradual removal of the nipple or pacifier from an infant's mouth while he or she is actively sucking to encourage protrusion and elevation of the tongue when trying to maintain contact with the object. 
In the postoperative period following frenotomy or frenuloplasty, tongue exercises are also often utilized to help prevent scarring and recurrence of ankyloglossia. Recommended exercises include protruding the tongue in and out of the mouth repetitively, touching the tongue to the posterior aspect of the upper teeth while the mouth is open widely, moving the tongue side-to-side, and sweeping food back and forth in the mouth with the tongue [7].

\section{Conclusion and pediatric considerations}

There is currently insufficient evidence to clearly associate ankyloglossia with difficulties in breastfeeding or speech due to large variations in diagnosis of ankyloglossia and outcomes measures. However, there are a number of studies that suggest surgical intervention through frenotomy or frenuloplasty is beneficial in improving breastfeeding efficacy. It is unclear at present if treating ankyloglossia improves latch and reduces maternal nipple pain during breastfeeding, as very little information exists on alternative, nonsurgical methods of managing ankyloglossia. Surgical intervention should be recommended with caution only in infants for whom ankyloglossia is clearly evident on physical examination and who have documented difficulties with breastfeeding. Procedures to treat ankyloglossia should only be performed by trained, experienced providers.

\section{Compliance with Ethical Standards}

\section{Conflict of Interest}

Sophie Shay, Rachel Mandelbaum, and Nina Shapiro declare that they have no conflict of interest.

Human and Animal Rights and Informed Consent

This article does not contain any studies with human or animal subjects performed by any of the authors.

\section{References and Recommended Reading}

Papers of particular interest, published recently, have been highlighted as:

- Of importance

$\bullet \quad$ Of major importance

1. World Health Organization, and UNICEF. Global Strategy for Infant and Young Child Feeding. World Health Organization; 2003.

2. Horton CE, Crawford HH, Adamson JE, Ashbell TS. Tongue-tie. Cleft Palate J. 1969;6:8-23.

3. García Pola MJ, González García M, García Martín JM, Gallas M, Seoane LJ. A study of pathology associated with short lingual frenum. ASDC J Dent Child. 2002;69(1):59-62. 12.

4. Kotlow LA. Ankyloglossia (tongue-tie): a diagnostic and treatment quandary. Quintessence Int Berl Ger 1985. 1999;30(4):259-62.
5. Ruffoli R, Giambelluca MA, Scavuzzo MC, et al. Ankyloglossia: a morphofunctional investigation in children. Oral Dis. 2005;11(3):170-4. doi:10.1111/j. 1601-0825.2005.01108.x.

6. Suter VGA, Bornstein MM. Ankyloglossia: facts and myths in diagnosis and treatment. J Periodontol. 2009;80(8):1204-19. doi:10.1902/jop.2009.090086.

7. Messner AH, Lalakea ML. The effect of ankyloglossia on speech in children. Otolaryngol-Head Neck Surg Off J Am Acad Otolaryngol-Head Neck Surg. 2002;127(6):539-45. doi:10.1067/mhn.2002. 1298231. 
8. Lalakea ML, Messner AH. Ankyloglossia: the adolescent and adult perspective. Otolaryngol-Head Neck Surg Off J Am Acad Otolaryngol-Head Neck Surg. 2003;128(5):746-52.

9. Messner AH, Lalakea ML. Ankyloglossia: controversies in management. Int J Pediatr Otorhinolaryngol. 2000;54(2-3):123-31.

10. Geddes DT, Langton DB, Gollow I, Jacobs LA, Hartmann PE, Simmer K. Frenulotomy for breastfeeding infants with ankyloglossia: effect on milk removal and sucking mechanism as imaged by ultrasound. Pediatrics. 2008;122(1):e188-94. doi:10.1542/peds.2007-2553.

11. Ricke LA, Baker NJ, Madlon-Kay DJ, DeFor TA. Newborn tongue-tie: prevalence and effect on breast-feeding. J Am Board Fam Pract Am Board Fam Pract. 2005;18(1):1-7.

12. Han S-H, Kim M-C, Choi Y-S, Lim J-S, Han K-T. A study on the genetic inheritance of ankyloglossia based on pedigree analysis. Arch Plast Surg. 2012;39(4):329-32. doi:10.5999/aps.2012.39.4.329.

13. Ballard JL, Auer CE, Khoury JC. Ankyloglossia: assessment, incidence, and effect of frenuloplasty on the breastfeeding dyad. Pediatrics. 2002;110(5), e63.

14. Moore GE, Ivens A, Chambers J, et al. Linkage of an Xchromosome cleft palate gene. Nature. 1987;326(6108):91-2. doi:10.1038/326091a0.

15. Hacham-Zadeh S, Garfunkel AA. Kindler syndrome in two related Kurdish families. Am J Med Genet. 1985;20(1):43-8. doi:10.1002/ajmg.1320200107.

16. Burdick AB, Ma LA, Dai ZH, Gao NN. van der Woude syndrome in two families in China. J Craniofac Genet Dev Biol. 1987;7(4):413-8.

17. Brooks JK, Leonard CO, Coccaro PJ. Opitz (BBB/G) syndrome: oral manifestations. Am J Med Genet. 1992;43(3):595-601. doi:10.1002/ajmg.1320430318.

18. Klockars T, Pitkäranta A. Pediatric tongue-tie division: indications, techniques and patient satisfaction. Int J Pediatr Otorhinolaryngol. 2009;73(10):1399-401. doi:10.1016/j.ijporl.2009. 07.004 .

19. Pauws E, Moore GE, Stanier P. A functional haplotype variant in the TBX22 promoter is associated with cleft palate and ankyloglossia. J Med Genet. 2009;46(8):555-61. doi:10.1136/jmg.2009.066902.

20. Braybrook C, Lisgo S, Doudney K, et al. Craniofacial expression of human and murine TBX22 correlates with the cleft palate and ankyloglossia phenotype observed in CPX patients. Hum Mol Genet. 2002;11(22):2793-804.

21. Haenig B, Schmidt C, Kraus F, Pfordt M, Kispert A. Cloning and expression analysis of the chick ortholog of TBX22, the gene mutated in X-linked cleft palate and ankyloglossia. Mech Dev. 2002;117(1-2):321-5.

22. Braybrook C, Doudney K, Marçano AC, et al. The T-box transcription factor gene TBX22 is mutated in X-linked cleft palate and ankyloglossia. Nat Genet. 2001;29(2):179-83. doi:10.1038/ng730.
23. Marçano ACB, Doudney K, Braybrook C, et al. TBX22 mutations are a frequent cause of cleft palate. J Med Genet. 2004;41(1):68-74.

24. Pauws E, Stanier P. FGF signalling and SUMO modification: new players in the aetiology of cleft lip and/or palate. Trends Genet TIG. 2007;23(12):631-40. doi:10.1016/j.tig.2007.09.002.

25. Harris EF, Friend GW, Tolley EA. Enhanced prevalence of ankyloglossia with maternal cocaine use. Cleft Palate-Craniofacial J Off Publ Am Cleft PalateCraniofacial Assoc. 1992;29(1):72-6. doi:10.1597/ 1545-1569(1992)029<0072:EPOAWM>2.3.CO;2.

26. Coryllos E, Genna CW, Salloum AC. Congenital tongue-tie and its impact on breastfeeding. Breastfeed Best Mother Baby. 2004;1-6.

27. Knox I. Tongue tie and frenotomy in the breastfeeding newborn. NeoReviews. 2010;11(9):e513-9. doi:10. 1542/neo.11-9-e513.

28. Hong P, Lago D, Seargeant J, Pellman L, Magit AE, Pransky SM. Defining ankyloglossia: a case series of anterior and posterior tongue ties. Int J Pediatr Otorhinolaryngol. 2010;74(9):1003-6. doi:10.1016/j. ijporl.2010.05.025.

29.• Pransky SM, Lago D, Hong P. Breastfeeding difficulties and oral cavity anomalies: the influence of posterior ankyloglossia and upper-lip ties. Int J Pediatr Otorhinolaryngol. 2015;79(10):1714-7. doi:10.1016/ j.ijporl.2015.07.033.

This paper is one of the few available in current literature that discusses the potential clinical significance of posterior ankyloglossia. They discuss the diagnosis of and management of posterior ankyloglossia in relation to breastfeeding.

30. O'Callahan C, Macary S, Clemente S. The effects of office-based frenotomy for anterior and posterior ankyloglossia on breastfeeding. Int J Pediatr Otorhinolaryngol. 2013;77(5):827-32. doi:10.1016/j. ijporl.2013.02.022.

31. Hogan M, Westcott C, Griffiths M. Randomized, controlled trial of division of tongue-tie in infants with feeding problems. J Paediatr Child Health. 2005;41(56):246-50. doi:10.1111/j.1440-1754.2005.00604.x.

32. Berry J, Griffiths M, Westcott C. A double-blind, randomized, controlled trial of tongue-tie division and its immediate effect on breastfeeding. Breastfeed Med Off J Acad Breastfeed Med. 2012;7(3):189-93. doi:10. 1089/bfm.2011.0030.

33. Buryk M, Bloom D, Shope T. Efficacy of neonatal release of ankyloglossia: a randomized trial. Pediatrics. 2011;128(2):280-8. doi:10.1542/peds.2011-0077.

$34 . \bullet$ Emond A, Ingram J, Johnson D, et al. Randomised controlled trial of early frenotomy in breastfed infants with mild-moderate tongue-tie. Arch Dis Child Fetal Neonatal Ed. 2014;99(3):F189-95. doi:10.1136/ archdischild-2013-305031.

This is one of the highlighted randomized controlled trials investigating the effect of frenotomy on breastfeeding measures. This paper found that there were no improvements on objective measures of breastfeeding following frenotomy, but there were increases in breastfeeding self-efficacy scores. 
35. Dollberg S, Botzer E, Grunis E, Mimouni FB. Immediate nipple pain relief after frenotomy in breast-fed infants with ankyloglossia: a randomized, prospective study. J Pediatr Surg. 2006;41(9):1598-600. doi:10. 1016/j.jpedsurg.2006.05.024.

36.• Finigan V, Long AJ. The effectiveness of frenulotomy on infant-feeding outcomes: a systematic review. Evid Based Midwifery. 2013;11(2):40-5.

In a systematic review of the literature on frenotomy and ankyloglossia, the authors state that frenotomy offered improvement in breastfeeding issues in over $50 \%$ of cases. They also found no literature on the effect of brenotomy and bottlefeeding.

37.•• Power RF, Murphy JF. Tongue-tie and frenotomy in infants with breastfeeding difficulties: achieving a balance. Arch Dis Child. 2015;100(5):489-94. doi:10. 1136/archdischild-2014-306211.

This is a systematic review on frenotomy and ankyloglossia, demonstrating the procedure as low-risk. The authors support careful patient selection for those undergoing frenotomy and recommend performing the procedure at 2-3 weeks of age.

38.• Francis DO, Chinnadurai S, Morad A, et al. Treatments for Ankyloglossia and Ankyloglossia With Concomitant LipTie. Rockville (MD): Agency for Healthcare Research and Quality (US); 2015. http://www.ncbi.nlm.nih. gov/books/NBK299120/. Accessed February 12, 2016. This paper is a systematic review on treatments for ankyloglossia. The authors highlight a paucity of data regarding nonsurgical treatment of ankyloglossia, and regarding the long-term outcomes of surgical intervention on outcomes other than breastfeeding.

39.• Francis DO, Krishnaswami S, McPheeters M. Treatment of ankyloglossia and breastfeeding outcomes: a systematic review. Pediatrics. 2015;135(6):e1458-66. doi:10.1542/peds.2015-0658.

This paper discusses treatment of ankyloglossia through a systematic review. They conclude that there may be an association between frenotomy and subjctive reports of improvement in breastfeeding, though the authors ultimately state that the strength of evidence in the available literature is low.

$40 . \bullet$ Webb AN, Hao W, Hong P. The effect of tongue-tie division on breastfeeding and speech articulation: a systematic review. Int J Pediatr Otorhinolaryngol. 2013;77(5):635-46. doi:10.1016/j.ijporl.2013.03.008.

In a systematic review of ankyloglossia, the authors found no association with speech difficulties.

41. Ito Y. Does frenotomy improve breast-feeding difficulties in infants with ankyloglossia? Pediatr Int Off J Jpn Pediatr Soc. 2014;56(4):497-505. doi:10.1111/ped. 12429.

42. Segal LM, Stephenson R, Dawes M, Feldman P. Prevalence, diagnosis, and treatment of ankyloglossia: methodologic review. Can Fam Physician Médecin Fam Can. 2007;53(6):1027-33.

43.• Chinnadurai S, Francis DO, Epstein RA, Morad A, Kohanim S, McPheeters M. Treatment of ankyloglossia for reasons other than breastfeeding: a systematic review. Pediatrics. 2015;135(6):e1467-74. doi:10.1542/ peds.2015-0660.
The authors concluded that there is insufficient evidence to assess the efficacy of frenotomy on nonbreastfeeding outcomes such as speech or social outcomes. They also found that frenotomy improved bottle feeding and tongue mobility in social situations such as eating ice cream, while there were limited cohort studies suggesting an improvement in speech articulation and intelligibility following frenotomy.

44. Matthews MK. Developing an instrument to assess infant breastfeeding behaviour in the early neonatal period. Midwifery. 1988;4(4):154-65.

45. Toner D, Giordano T, Handler SD. Office frenotomy for neonates: resolving dysphagia, parental satisfaction and cost-effectiveness. ORL-Head Neck Nurs Off J Soc Otorhinolaryngol Head-Neck Nurses. 2014;32(2):6-7.

46. Rose K, Kasbekar AV, Flynn A, De S. Developing a nurse-delivered frenulotomy service. OtolaryngolHead Neck Surg Off J Am Acad Otolaryngol-Head Neck Surg. 2015;152(1):149-52. doi:10.1177/ 0194599814554554 .

47. Mettias B, O'Brien R, Abo Khatwa MM, Nasrallah L, Doddi M. Division of tongue tie as an outpatient procedure. Technique, efficacy and safety. Int J Pediatr Otorhinolaryngol. 2013;77(4):550-2. doi:10.1016/j. ijporl.2013.01.003.

48. Rowan-Legg A. Ankyloglossia and breastfeeding. Paediatr Child Health. 2015;20(4):209-13.

This article summarizes the diagnosis and treatment of ankyloglossia. The authors conclude that a careful physical examination is necessary to rule out other oral anomalies and that surgical intervention should be reserved for infants who would clearly benefit from the procedure.

49. Lalakea ML, Messner AH. Frenotomy and frenuloplasty: if, when, and how. Oper Tech Otolaryngol-Head Neck Surg. 2002;13(1):93-7. doi:10.1053/otot.2002.32157.

50. Ovental A, Marom R, Botzer E, Batscha N, Dollberg S. Using topical benzocaine before lingual frenotomy did not reduce crying and should be discouraged. Acta Paediatr Oslo Nor 1992. 2014;103(7):780-2. doi:10.1111/apa.12654.

This paper is one of the few that focuses on the use of local anesthesia in lingual frenotomy. Through a small randomized controlled trial, the authors concluding that there was no perceived benefit in pain reduction with the use of topical benzocaine.

51. Natonal Institute for Health and Care Excellence. Division of ankyloglossia (tongue-tie) for breastfeeding | Guidance and guidelines | NICE. https://www.nice.org.uk/guidance/ipg149. Accessed February 14, 2016.

52. De Santis D, Gerosa R, Graziani PF, et al. Lingual frenectomy: a comparison between the conventional surgical and laser procedure. Minerva Stomatol. August 2013.

53. Fiorotti RC, Bertolini MM, Nicola JH, Nicola EMD. Early lingual frenectomy assisted by CO2 laser helps prevention and treatment of functional alterations caused by ankyloglossia. Int J Orofac Myol Off Publ Int Assoc Orofac Myol. 2004;30:64-71. 
54. Olivi G, Signore A, Olivi M, Genovese MD. Lingual frenectomy: functional evaluation and new therapeutical approach. Eur J Paediatr Dent Off J Eur Acad Paediatr Dent. 2012;13(2):101-6.

55. Akpinar A, Toker H, Lektemur Alpan A, Calisir M. Postoperative Discomfort After Nd: YAG laser and conventional frenectomy: comparison of both genders. Aust Dent J. 2015. doi:10.1111/adj.12333.

56. Barot VJ, Vishnoi SL, Chandran S, Bakutra GV. Laser: The torch of freedom for ankyloglossia. Indian J Plast Surg Off Publ Assoc Plast Surg India. 2014;47(3):418-22. doi:10.4103/09700358.146630 .

57. Haytac MC, Ozcelik O. Evaluation of patient perceptions after frenectomy operations: a comparison of carbon dioxide laser and scalpel techniques. J Periodontol. 2006;77(11):1815-9. doi:10.1902/jop. 2006.060043.

58. Zeinoun T, Nammour S, Dourov N, Aftimos G, Luomanen M. Myofibroblasts in healing laser excision wounds. Lasers Surg Med. 2001;28(1):74-9. doi:10.
1002/1096-9101(2001)28:1<74::AID-LSM1019>3.0. $\mathrm{CO} ; 2-\mathrm{B}$

59. Heller J, Gabbay J, O'Hara C, Heller M, Bradley JP. Improved ankyloglossia correction with four-flap Zfrenuloplasty. Ann Plast Surg. 2005;54(6):623-8.

60. Choi Y-S, Lim J-S, Han K-T, Lee W-S, Kim M-C. Ankyloglossia correction: Z-plasty combined with genioglossus myotomy. J Craniofac Surg. 2011;22(6):2238-40. doi:10.1097/SCS. ob013e3182320122.

61. Riskin A, Mansovsky M, Coler-Botzer T, et al. Tonguetie and breastfeeding in newborns-mothers' perspective. Breastfeed Med. 2014;9(9):430-7. doi:10.1089/ bfm.2014.0072.

This paper offers the perspective of lactation consultants in the management of ankyloglossia and breastfeeding difficulties.

62. Genna CW. Supporting Sucking Skills in Breastfeeding Infants. Jones \& Bartlett Publishers; 2012.

63. Whitman CL, Rankow RM. Diagnosis and management of ankyloglossia. Am J Orthod. 1961;47(6):4238. doi:10.1016/0002-9416(61)90221-4. 